\title{
Educational Qualification and Family Planning Practices Among Married Persons in Southwest, Nigeria
}

\author{
DR. (MRS.) Fasiku, Adesola Mercy \\ Department of Social Studies, College of Education, Ikere - Ekiti, Ekiti State, Nigeria \\ Emua, Charles Imoisi \\ Department of Social Studies, College of Education, Ikere - Ekiti, Ekiti State, Nigeria
}

\begin{abstract}
This study examined the relationship between educational qualification and family planning practices among married persons in Southwest Nigeria. Descriptive research design of the survey type was adopted for this study and the sample consisted of one thousand and two hundred $(1,200)$ married persons. Multistage random sampling technique was used to select the sample. Information was collected for the study through the administration of questionnaire to the respondents. Data obtained were analysed using mean, standard deviation, ANOVA and regression analysis. The result revealed that educational qualification of married persons will significantly influence the family planning practices. It was concluded that married person with high educational qualification will definitely plan their family by giving birth to few children, It was therefore recommended that married persons need to improve on their educational status in order to increase the level of family planning practices. Also they should see the need to plan and space child birth.
\end{abstract}

Keywords: Marriage, Family, Educational Qualification, Family Planning Practices, Child Spacing.

DOI: $10.7176 /$ RHSS/10-6-05

Publication date:March $31^{\text {st }} 2020$

\section{Introduction}

Marriage as a social institution has been described as a socially sanctioned sex relationship involving two or more people of the opposite sex, which is expected to endure beyond the time required for gestation and birth of children (Amiteshwar, 2006). Through marriage, rights roles and new social relationships are created not only between the spouses but also between the kinsmen of the spouses. That is why Action Health Incorporated (2003), posit that marriage is a legal and social commitment that two people make to share their lives and family responsibilities. It is used in qualifying an important institution across the universe and most people have an erroneous assumption that the utmost purpose of marriage is for procreation.

Marriage is a universal concept across all cultures in the globe but the practices vary based on the culture and the people involved. There are different types of marriage among which are polygamy, monogamy, endogamy, exogamy, sororate, levirate, child marriage among others and any of these types of marriages can produce monogamy or polygamy family.

In respect of polygamy family, that is, a situation where a man marries more than a wife, the union of a man and more than one wife leads to the birth of many children which can promote societal problems such as malnutrition, increase in crime rate, child abuse and others. Human being are always son the look out for solutions to their numerous problems. In contemporary Nigeria society, the problems of infant and maternal mortality, overpopulation, housing, unemployment, couple separation and divorce have gained attention of researchers with a view of finding solutions to them, hence, raising the living standard of people and establishing stable homes is very important. Reproductive heath has also taken a central position in order to stem the tide of societal problems that may be generated from sexual mismanagement and to underscore manageable family size and peaceful family. This, however, cannot be achieved by mere fiat or rhetoric but by concerned efforts of the concerned people regarding advocacy for the practice of Family Planning irrespective of their educational background. For the couple to enjoy healthy sexual relationship which is the first paramount obligation between the couple, they need to adopt family planning services to allay fears of unwanted pregnancies (Alade 2014).

Family planning is simply a way of maintaining reasonable interval and limitation in child bearing process. This is to say, that a woman should rest after giving birth to the first child for at least two (2) years before another birth. It is a way of preventing unwanted pregnancy a means of sexual gratification. Family Planning is a deliberate effort by couples to regulate the number of children and spacing of birth. It aims at improving family life at a micro level in order to contribute to sustainable development in macro level.

Education helps in the improvement of an individuals personality, self-confidence, and self-esteem, in that, women's education usually bring about low fertility rate, longer life expectations, lower infant and maternal mortality.(Olowokeeere,2014). Besides, Family Planning seems to be commonly practiced among the educated couples. This may be due to their high level of awareness and exposure concerning the pros and cons of having many children, and than of having fewer children. It appears that educated couples, most especially in a family 
where the woman is educated with high level of exposure, will see the need to maintain sizeable family by using any family planning methods to space the number of conception and child birth, which will assist her health ,children and the entire family. Also they might have been exposed to what it takes to have a decent family and maintain it by making provision for good family welfare, like provision of food, quality education, good accommodation and lots of other benefits are taken seriously.

On the other hand, the less educated couple may lack the necessary knowledge about the benefits derivable from practicing Family Planning. Most of them believe that pregnancy is God's gift and blessing which no one can reject or refuse to collect. Some educated husbands also believe that when a woman adopts Family Planning, there is likelihood for her to become infidel and promiscuous. On this note, such husband may ask the woman not to adopt it or if already practicing she should quit the practices or pack out of their matrimonial home which may aggravate marital problem and thereby, result to divorce. Also, Family Planning is not practiced by the less educated couple as a result of ignorance of some men, coupled with their erroneous beliefs that any woman that practices Family Planning would contact disease or have health problems, to those men, even child spacing is a taboo. They believe it could also lead to barrenness. All these assumptions, when not properly managed by couples, may affect the stability of homes and their children.

Based on the above observation, a pertinent question that is raised in this study is, will educational qualification influence the family planning practices? It is against the background that the research work is out to examine the influence of educational qualification on family planning practices among married person in South West, Nigeria.

\section{Literature Review \\ Family Planning}

Adaka (1982), describes Family Planning as part of Planned Parenthood fertility control, or contraception control in limiting or spacing out pregnancies either for socio-economic, health or population control purposes. In the researcher's point of view, the scholar's citation is very right as it gives the comprehensive meaning of the concept of Family Planning. The World Health Organization (WHO) (2015) defines Family Planning as "a way of thinking and living that is adopted voluntarily upon the basis of knowledge, attitudes and responsible decisions by individuals and couples, in order to promote health and welfare of the family group, and thus contributing effectively to the social development of the country".

However, Ebele (2006) defines Family Planning as having the number of children at interval, that is suitable for the couples in order to ensure adequate care, as well as using birth control and contraceptive for controlling the number and spacing of children. Family Planning here, is seen as controlling the number of children with the use of birth control and contraceptive measures. Also, it was revealed that Family Planning is an organized effort to assist people to have the number of children they desire, and to space them accordingly as they choose (Ebele, 2006).

Action Health Incorporated (AHI) (2003) saw Family Planning as an emotionally charged subject. To many, it is the name given to ways in which couples attempt to control their fertility. It also submitted that, the reality of our lives today, however, demands that we re-assess cultural tenets about children and family size, within the context of today's need and pressure. It is most usually applied to a couple who wish to limit the number of children they have, or to control the timing of pregnancy. Family Planning allows individuals and couples to anticipate and attain their desired number of children, spacing and timing of their birth. This can be achieved through the use of contraceptives and other method such as the use of Condom, Implant, and Injection. IUCD (Internet http//www.globalhealth.com).

Delano (2010) saw Family Planning as a means by which individuals or couples space the process of conception and child birth at interval, mutually determined by both partners, in order to have the desired number of children that they can conveniently maintain. From the above definitions, it can be deduced that Family Planning is working out a plan with one's partner, on how to deal with procreation within the context of a sexual relationship. This covers many things such as when and why to get pregnant, the number of children that is wanted, how to deal with fertility issues, how to avoid unwanted pregnancy, whether to consider an abortion, if an unwanted pregnancy occurs etc. It also concerns issues of having children that are planned for, and not children conceived by accident or chance. One can conveniently say that, the whole essence of Family Planning revolves on the health, survivals, and developments of the family and progress of the entire society.

Also in working towards making Family Planning a way of life for all families in social and economic developments, some association advocates and firmly believes that, knowledge and practice of Family Planning is a basic human right and an essential element of responsible parenthood, stable family life and positive contribution towards social harmony and national development. Family Planning also offers individuals opportunities to plan and space their pregnancies, in order to achieve personal goals and self-sufficiency. Also, it is observed that it will reduce unintended pregnancies in order to avoid the poor outcomes of health, social and economic problems, related to unintended pregnancies. To promote the health of mothers by providing basic reproductive health care 
to women in needs (Sweta, 2012).

Family Planning is a key part of the commitment to empowering women and improving family. In almost every surroundings, the objectives of Family Planning commonly highlighted included unwanted pregnancy prevention, extensive population growth reduction and health improvement of women; children and population as a whole. Family Planning benefits the health and well - being of women and families throughout the world. Goals in Family Planning should include balancing the desire for children with emotional, physical and financial needs, or if you don't wish to have children, it's important to recognize this, and plan accordingly. In the same vein, knowledge and practice of Family Planning is a basic human right and an essential element of responsible parenthood, stable family life and positive contribution towards social harmony and national development. Olaitan (2011), highlighted that a myriad of different factors influence a person's personal decisions about what types of Family Planning method he should use. The factors are as follows: Effectiveness, religion, cost, health risk permanence, partner involvement and some other socio-economic factors. According to him, effectiveness comes in when couples who are not in a financial or emotional situation to have children might opt for the most effective type of Family Planning in order to avoid Pregnancy whereas couple with casual approach towards parenthood might choose a less certain form of contraception as a result of Family Planning practices between couples of different religion, that is to say, if the couples are not of the same religious belief, taking a mutual decision may generate problems.

\section{Concept of Education}

Education is the process of facilitating learning or the acquisition of knowledge, skills, values, beliefs, and habits and its various methods includes storytelling, discussion, teaching, training and directed research.

Education has originated from the latin term "educare" which mean "to lead forth or " to raise" this indicate that education seeks to nourish the good qualities in man and draw out the best in every individual. Education seeks to develop the image inner capacities of man.

When an individual is educated there is tendency to give him some desirable knowledge, understanding, skills, interests, attitudes and critical thinking. Education is so important in the society, in that, will make people think critically about various issues of life and take decisions about them been free from bias, prejudices, superstitions, and blind beliefs. All these definitions lies on how important are the education to the development of individual and the society at large. That is to say, an educated married persons will definitely improve their practices on Family Planning.

\section{Effects of Education on Family Planning Practices}

Education, whether formal or informal is the fulfilling of our endowed intellectual capacities. It is generally perceived to be the process of discipline through training and study in the acquisition of skills and knowledge. In the wider sense, education could mean the training of the entire persons to enable him make himself fit for living in a society (Awopetu, Fasiku and Daramola, 2013). From the above definition, one could see how education can change one's behaviour to fit into the society.

Olowookeere (2014) declared that education is a process of becoming critically aware of one's reality in a manner that leads to effective action on it. The author stressed further that an educated man or woman understands his or her world well enough to deal with it effectively; such men or women, if they existed in good numbers would not leave the absurdities of the present world unchanged. She opined further that education is knowledge and knowledge brings about light and remove ignorance.

Education confers a range of benefit on individuals and societies. Achem (2005) wrote that countries with better educated citizens tend to have healthier population, as educated individuals make more informed health choices, live longer, and have healthier children more so, when the citizens of the countries are educated the fertility tend to grow slowly and that education affects marital stability and concluded that the more the education of the spouses, the more stable their marriage will be. In the same direction, Gottman \& Notarius (2002) observed that men who complete college have lower probability of divorce than men who complete only high school, or who leave college without graduating. This simply means that education of the spouse makes for an increase sense of responsibility within marriage.

It has been observed that level of education has a lot to do with the practice of family planning, in that women that are relatively well educated have been shown to have strong trend towards declining fertility and increasing utilization of contraceptives (Mkangi, 2001). Also, it was discovered that secondary or higher education attainment was more likely to be associated with the use of contraception (Ross et all,2002). Education affects a range of factors associated with the socio economic development of women including fertility, health and economic achievement (Lutz, Cuaresma and Sanderson, 2008). Female education, particularly completion of primary school and graduation into secondary school has been liked with lower fertility

Azar (2002) said that little education can results in higher levels of fertility. In the same vein, Epstein \& Baucom (2002) posit that generally higher levels of education are associated with lower levels of fertility. From 
the researcher's point of views, one can deduce, access to education drives the desire to limit fertility and the demand for access to contraception. In conclusion, it appears that the higher the educational attainment, especially the women, the lower the fertility rate, that is to say, the illiterate women seem to have higher fertility in the study.

\section{Research Questions}

The following research questions were raised for the study.

i. Will educational qualification influence the family planning practices among married persons in Southwest Nigeria?

ii. Will educational qualification of married persons predict family planning practices in Southwest, Nigeria?

\section{Research Hypotheses}

The following hypotheses were formulated for the study.

$\mathrm{HO}_{1}$ : Educational qualification will not significantly influence the Family Planning practices and marital stability among married persons in Southwest Nigeria.

$\mathrm{HO}_{1}$ : Educational qualification will not significantly predict family planning practices among married persons in Southwest, Nigeria

\section{Research Method}

The descriptive research design of the survey type was used for this study. The population for the study consisted of all married persons between the age group 15 to 49 years for women and 15 years and above for men in Southwest, Nigeria. One thousand and two hundred (1200) married persons (male/female) in their reproductive ages were selected through Multistage random sampling technique. Three states were randomly selected from the six states in Southwest, Nigeria after which five Local Government Areas from each of the three states were also randomly selected making fifteen local governments areas in all. State capital of each state was purposively selected as urban location and four local governments outside the state capital were purposively selected as rural location. In each of the local governments Married persons were selected from houses in each street through simple random sampling techniques. The instrument used was a structured questionnaire designed by the researcher to elicit information from the respondents. The validity of the instrument was ascertained by some experts in Social Science Education, Test, Measurement and Evaluation, Guidance and Counseling and Social Sciences, the test retest reliability procedure was used to ascertain the reliability of the instrument. The two hypotheses raised were tested at 0.05 level of significance.

\section{Results}

The result of the research questions and hypotheses were presented below.

Hypothesis 1: Educational qualification will not significantly influence the Family Planning Practices among Married persons in Southwest, Nigeria.

Scores on Family Planning Practices among married persons in Southwest, Nigeria were computed and subsequent compared for statistical significance using Analysis of Variance (ANOVA) at 0.05 level of significance on the basis of educational qualification. The result is presented in Table 1

Table 1: ANOVA showing Family Planning Practices in Southwest, Nigeria on educational qualification

\begin{tabular}{|c|c|c|c|c|c|c|c|}
\hline Variable & Source & SS & DF & MS & $F_{\text {cal }}$ & $F_{\text {table }}$ & $\mathbf{P}$ \\
\hline \multirow[t]{3}{*}{$\begin{array}{l}\text { Family } \\
\text { Planning }\end{array}$} & $\begin{array}{l}\text { Between } \\
\text { groups }\end{array}$ & 18046.820 & 8 & 2255.853 & \multirow{3}{*}{15.960} & \multirow{3}{*}{1.940} & \multirow{3}{*}{0.00} \\
\hline & $\begin{array}{l}\text { Within } \\
\text { groups }\end{array}$ & 168343.766 & 1191 & 141.347 & & & \\
\hline & Total & 186390.587 & & & & & \\
\hline
\end{tabular}

${ }^{*} \mathbf{P}<\mathbf{0 . 0 5}$

Table 1 depicts that educational qualification of married persons will significantly influence the Family Planning Practices $\left(\mathrm{F}_{\mathrm{cal}}=8.784, \mathrm{P}<0.05\right)$ of married persons in Southwest, Nigeria and the $\mathrm{F}_{\mathrm{tab}}$ is 1.940 which is less than Fcal at 0.005 level of significance. Therefore, the null hypothesis is rejected. This implies that educational qualification of married persons will significantly influence the family planning practices in Southwest, Nigeria. 
Table 2: Scheffe Post-Hoc test showing Family Planning of married persons in Southwest, Nigeria by Educational qualification.

\begin{tabular}{|c|c|c|c|c|c|c|c|c|c|c|c|c|}
\hline & & B.Sc & HND & SSCE & ND & PRY & NCE & ILLITERATE & NRN & $\begin{array}{l}\text { GRD } \\
\text { II }\end{array}$ & $\mathbf{N}$ & MEAN \\
\hline \multirow{9}{*}{$\begin{array}{l}\text { Family } \\
\text { Planning }\end{array}$} & B.sc & & & & & & & & * & $*$ & 299 & 33.95 \\
\hline & HND & & & & & & & & * & & 189 & 31.95 \\
\hline & $\mathrm{ND}$ & & & & & & & & $*$ & & 118 & 31.95 \\
\hline & PRY & & & & & & & & & & 55 & 31.03 \\
\hline & $\mathrm{NCE}$ & & & & & & & & * & $*$ & 183 & 33.04 \\
\hline & SSCE & & & & & & & & * & & 247 & 29.60 \\
\hline & ILLITERATE & & & & & & & & & $*$ & 16 & 31.50 \\
\hline & NRN & & & & & & & & & & 63 & 45.26 \\
\hline & GRD II & & & & & & & & & & 30 & 39.00 \\
\hline
\end{tabular}

$* \mathbf{P}<\mathbf{0 . 0 5}$

The result shows that there is a significant difference between the family planning practices of NRN and B.sc, HND, ND, NCE and school certificate at 0.005 level of significance. The mean difference between the family planning practices of Grade II and B.sc, NCE and Grade II, Illiterate persons and Grade II certificate holders is significant at 0.05 level in each case.

\section{Hypothesis 2}

$\mathrm{Ho}_{1}$ : Educational qualification will not significantly predict Family Planning Practices among Married persons in Southwest, Nigeria.

Table 2: Regression analysis Showing Predictors of Family Planning Practices in Southwest, Nigeria

\begin{tabular}{|c|c|c|c|c|c|c|c|c|}
\hline Model & B & Std. Error & Beta & $\mathbf{T}$ & Sig. T & $\mathbf{R}$ & $\mathbf{R}^{2}$ & $\mathbf{F}$ \\
\hline Constant & 48.954 & 1.261 & & 38.806 & 0.000 & \multirow{21}{*}{0.347} & \multirow{21}{*}{0.120} & \multirow{21}{*}{8.065} \\
\hline B1 & 0.838 & 0.459 & 0.061 & 1.824 & 0.068 & & & \\
\hline $\mathrm{B} 2$ & 0.025 & 0.711 & 0.001 & 0.035 & 0.972 & & & \\
\hline B3 & 1.397 & 0.36 & 0.079 & 1.671 & 0.095 & & & \\
\hline B4 & 2.243 & 0.909 & 0.121 & $2.467^{*}$ & 0.014 & & & \\
\hline B5 & 0.182 & 0.764 & 0.010 & 0.238 & 0.812 & & & \\
\hline B6 & 0.433 & 0.772 & 0.023 & 0.561 & 0.575 & & & \\
\hline B7 & 1.141 & 0.531 & 0.077 & $2.149^{*}$ & 0.032 & & & \\
\hline B8 & 2.742 & 0.719 & 0.150 & $3.814^{*}$ & 0.000 & & & \\
\hline B9 & 0.457 & 0.625 & 0.029 & 0.731 & 0.465 & & & \\
\hline B10 & 1.580 & 0.600 & 0.093 & $2.635^{*}$ & 0.009 & & & \\
\hline B11 & 0.711 & 0.656 & 0.042 & 1.084 & 0.279 & & & \\
\hline B12 & 0.770 & 0.644 & 0.046 & 1.196 & 0.232 & & & \\
\hline B13 & 0.098 & 0.677 & 0.006 & 0.144 & 0.885 & & & \\
\hline B14 & 0.278 & 0.656 & 0.017 & 0.424 & 0.671 & & & \\
\hline B15 & 2.669 & 0.444 & 0.196 & $6.011^{*}$ & 0.000 & & & \\
\hline B16 & 0.905 & 0.596 & 0.056 & 1.519 & 0.129 & & & \\
\hline $\mathrm{B} 17$ & 0.179 & 0.630 & 0.011 & 0.284 & 0.777 & & & \\
\hline B18 & 0.240 & 0.578 & 0.016 & 0.415 & 0.678 & & & \\
\hline B19 & 1.495 & 0.604 & 0.098 & $2.475^{*}$ & 0.013 & & & \\
\hline B20 & 0.920 & 0.570 & 0.056 & 1.614 & 0.107 & & & \\
\hline
\end{tabular}

\section{${ }^{*} \mathbf{P}<\mathbf{0 . 0 5}$}

$\underline{\text { KEY }}$

$\overline{\mathbf{B}-} \quad$ Unstandardize / raw data base. Beta - Refined / processed one. $\mathbf{R}$ - Coefficient of regression

$\mathbf{R}^{\mathbf{2}}$ - Joint contribution of all the variables.B1: Chance method B2: Emergency contraceptive

B3: Contraceptive injection B4: Any contraceptive B5: Local herbs B6: Oral cooked concoction food B7: Basal body temperature method B8: Cervical mucus method B9: Spermicidal cream or foaming tablet B10: Symtothermal method (Combined method) B11: Norplant method B12: Douching method B13: LactationalamenorrhoeaB14: Male vasectomy B15: Female tubal ligation B16: Scarification method B17: Charmed ring B18: Waist band B19: Charmed padlock B20: Arm band

The effect of family planning practices accounted for about $12 \%\left(\mathrm{R}^{2}=0.120\right)$ of the observed married persons. The remaining $88 \%$ unexplained variation in educational qualification is largely due to other variables outside the regression model. The composite relationship between family planning practices and marital stability is positive, moderately low and significant at 0.05 level of significance $(\mathrm{R}=0.347, \mathrm{p}<0.05)$.

The single best predictor of marital stability among the family planning practices is contraceptive injection 
with a beta weight of $0.196(19.6 \%)$. This is closely followed by charm padlock (Beta weight $=0.150 ; 15 \%)$, arm band $($ Beta weight $=0.121 ; 12.1 \%)$ and emergency contraceptive after sex (Beta weight $=0.098 ; 9.8 \%)$ while douching method constitutes the least predictor of marital stability among married persons in Southwest, Nigeria with a beta weight of $0.001(1 \%)$.

Only the effect of arm band $(\mathrm{t}=2.467, \mathrm{P}<0.05)$, local herbs $(2.149, \mathrm{P}<0.05)$, charm padlock $(\mathrm{t}=3.814, \mathrm{P}<0.05)$, basal temperature method $(\mathrm{t}=2.635, \mathrm{P}<0.05)$, contraceptive injection $(\mathrm{t}=6.011, \mathrm{P}<0.05)$ and emergency contraceptive after sex $(\mathrm{t}=2.475, \mathrm{P}<0.05)$ on marital stability is significant at 0.05 level of significance among family planning practices.

\section{Discussion of Findings}

The results revealed that educational qualifications of married persons will significantly influence the family planning practices. The reason may not be far from the fact that countries with better educated citizen tend to have healthier population as they will make more informed health choices, live longer and have healthier children and more so the fertility tends to grow more slowly. Generally, higher levels of education are associated with lower levels of fertility. This implies that access to education drives the desire to limit fertility and the demand for access to contraception which means that the higher the educational attainment especially for the women, the lower the fertility rate.

Another finding from the study shows that the single best predictor among family planning practices is contraceptive injection, closely followed by charm padlock, arm band and emergency contraceptive after sex. Hence, where there is happiness and contentment expressed by family members, such family could be said be stable. However, some married couples still do not believe that planning family can make their marriage stable.

\section{Conclusion and Recommendations}

Based on the findings of the study, it was concluded that despite various types of family planning, few were adopted which leads to low practice of family planning among married persons in Southwest, Nigeria. It was submitted that educational qualification especially for women is associated with the practice of family planning. This implies that illiterate couples always have tendency to give birth to many children that they may not be able to cater for. On this note, couples must be encouraged to be educated. It was also recommended that Married persons should be encouraged by marriage counselors and religious leaders to make considerate and beneficial decision on how to manage their family size through family planning practices for home stability and the Federal, State and Local Government should educate spouses and implement the world declaration for women education, that is, there should be free universal and compulsory education for all especially women.

\section{References}

Adaka, A. C. (1982). The need and methods of family planning ( $2^{\text {nd }}$ Editions). Ila - Orangun: Fermsoel Press.

Alvergue, A., Lawson, D. W., Clarke, P. M. R., Gurmu, E. \& Mace, R. (2013). Fertility parental investment and the early adoption of modern contraception in rural Ethiopia. American Journal of Human Biology. 25, 107 $-115$.

Amiteshwar, R. (2006). Working and non-working: Preparedness for family life. Delhi and Hissar city of Haryana. India: Mittal Publication

Dixon -Mueller, R. \& German, A. (2007). Fertility regulation and reproductive health in the millennium development goals: The search for a perfect indicator. America Journal of Public Health. 97(1), 45 - 5

Ebele, S. N. (2006). Women empowerment and economic development: A case of Idemili North Local Government of Anambra state of Nigeria (1988)

George, I. N. (2002). Marital role adjustment and satisfaction among Ibiobio workersin Akwa Ibom State. Unpublished Ph.D. Dissertation, Faculty of Education, University of Calabar, Calabar.

Gloria, B. \& Keith, M. (1994). Families and intimate Relationship. Publisher: Megraw-Hill College

Gottman, J. M. (2000). Why marriages fail.In K. M. Galvin \& P. J. Cooper (Eds.). Making connections: Reading in Relation communication ( $2^{\text {nd }}$ ed). Pp. 216 - 223. Los Angeles, CA: Roxbury Publishing Company.

Grady, W. R., Klepinger, D. H. \& Nelson - Wally, A. (2000). The contraceptive, characteristics: The perceptions and priorities of men and women family planning perspectives. 31(4), $168-175$.

Heaton, T. B. (2002). Factors contributing to increasing marital stability in the United States. Journal of Family Issues 23(3), $292-409$

Linna, W. D. \& Crane, R. (2001). The relationship between Marital satisfaction, marital stability, nuclear family, triangulation and childhood depression. The American Journal of Family Therapy. 29, 337- 347.

Olaitan, O. L. (2011). Factors influencing the choice of family planning among couples in Southwest, Nigeria. International Journal of Medicine and Medical Science. 3(7), 227-232.

Owuamanam, D. O. (2008). Sexual Networking among Youth in Southwestern Nigeria. Health Transition Review. $5,57-66$ 
Teachman, J. (2002). Stability across cohorts in divorce risk factors. Demographic. 39, 331 - 351

Uwe, E. A. (2002). Infertility marriage.In E. A. Uwe and A. E. Obot, (Eds). Marriage counselling: Issues and solutions. Nigeria: Pyamid Printers.

WHO (2015). Family planning/ contraception. Available atwww.who.int/me diacenter/fact sheets/fs351/en/ 